\title{
GÉNESIS Y DESARROLLO DE LOS CUATRO CENTROS PARROQUIALES DEL POLÍGONO DE COYA (VIGO, 1953-1981)
}

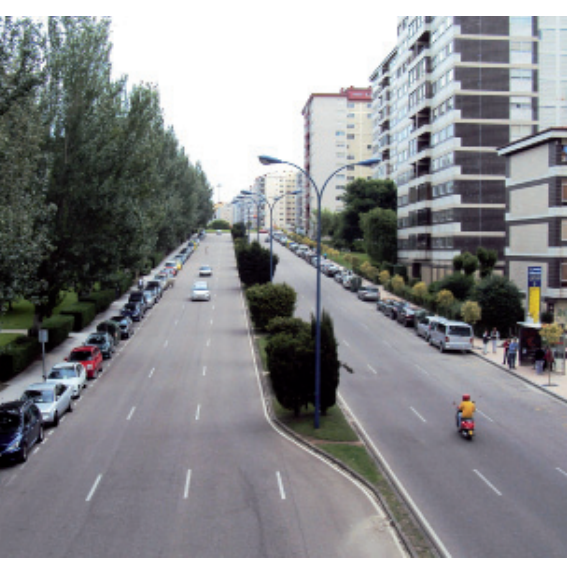

Marta Vilas Rodríguez y Esteban Fernández-Cobián

Genesis and development of the four parish centers of the Coya polygon (Vigo, 1953-1981)

Boletín Académico. Revista de investigación y arquitectura contemporánea

Escuela Técnica Superior de Arquitectura. Universidade da Coruña

elSSN 2173-6723

unw.boletinacademico.com

Número 3 (2013)

Páginas 15-28

Fecha de recepción 02.10.2012

Fecha de aceptación 22.01.2013

https://doi.org/10.17979/bac.2013.3.0.993

\section{Resumen}

Este artículo relata la historia de los cuatro centros parroquiales del polígono de Coya (Vigo), una parte significativa de la ciudad que, a pesar de haber sido proyectada durante los años cincuenta, no se acabó de construir hasta bien entrados los años ochenta. Durante este tiempo, los centros parroquiales fueron trascendiendo su función litúrgica primaria, y a través de unas arquitecturas abiertas que sufrieron la variación de sus programas, la escasez económica y los vaivenes sociales, colaboraron en el cosido del nuevo tejido urbano con la ciudad existente. Hoy en día, siguen aportando a Coya buena parte de su identidad.

\section{Abstract}

This article tells the story of the four parish centers of the Coya polygon (Vigo), a significant part of the city which, despite having been designed in the fifties, was not finished until well into the eighties. During this time, the parish centers were transcending their liturgical function, and through open architectures that suffered a variation of its programs, economic scarcity and social fluctuations, collaborated on the new urban tissue stitched with the existing city. Today, they continue to make to Coya good part of their identity.

\section{Palabras clave}

Vigo, Coya, Iglesia, Centro parroquial

\section{Keywords}

Vigo, Coya, Church, Parish center 


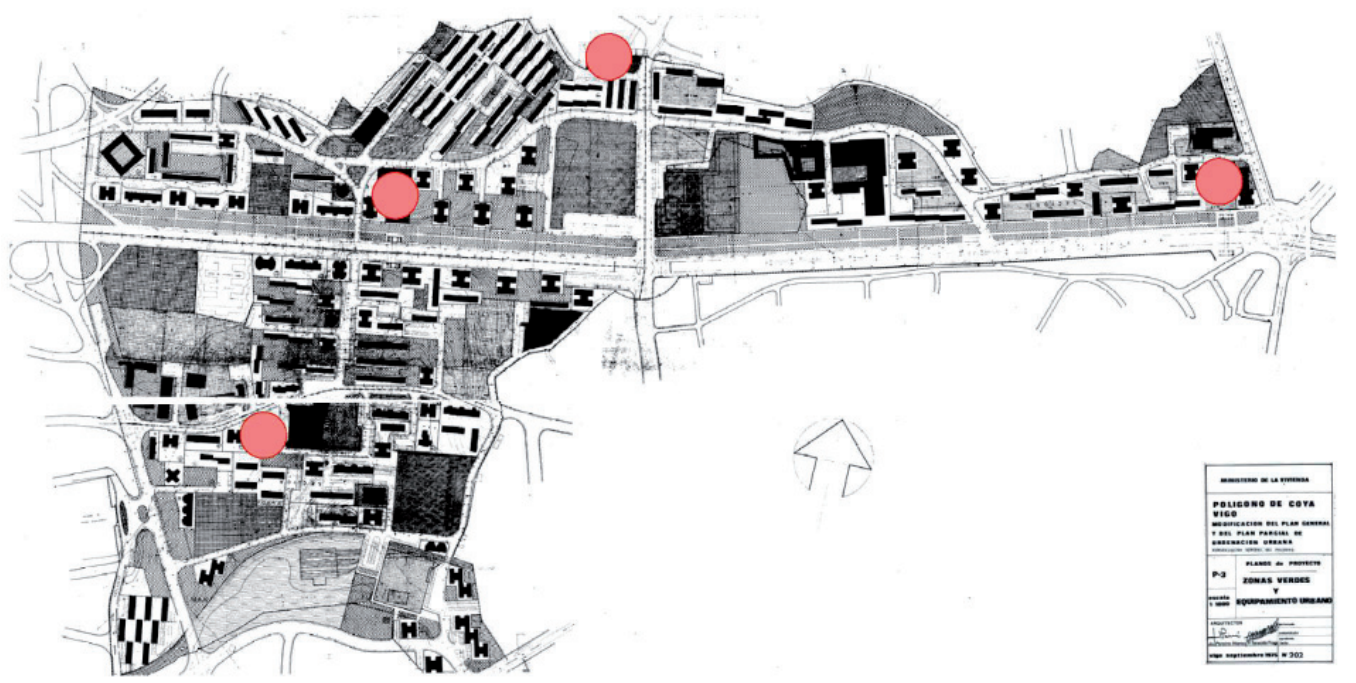

1 (En la página anterior) La avenida de Castelao, eje viario del polígono de Coya, en la actualidad

2 Ubicación de los centros parroquiales el polígono de Coya (Vigo). De izquierda a derecha: Santo Cristo de la Victoria, Virgen del Rocío, San Martín de Coya y Nuestra Señora del Perpetuo Socorro

\section{EL POLÍGONO DE COYA Y SUS EQUIPAMIENTOS RELIGIOSOS}

El polígono de Coya surgió en Vigo (Pontevedra) como consecuencia de la reforma administrativa del Estado que se acometió a partir de 1956 y se concretó en los Polos de Desarrollo (Fig. 01). Los terrenos del polígono se extendieron sobre la antigua parroquia de San Martín de Coya. En 1958 se decretó la constitución de las nuevas parroquias del Santísimo Cristo de la Victoria y San Antonio de la Florida, esta última fuera del polígono, y en 1970 de otras dos: el Perpetuo Socorro y la Virgen del Rocío'.

En la actualidad, en el ámbito de Coya se ubican cuatro edificios que podríamos denominar como «centros parroquiales», esto es, edificios en los que los espacios dedicados al culto que conforman la iglesia se complementan con otra serie de servicios, como aulas, salas de actos o reuniones y oficinas, además de la residencia del párroco. Son edificios en los que se desarrolla una actividad más extensa que la estrictamente cultual, y que, por lo tanto, constituyen equipamientos dotacionales, en toda la extensión del término (Fig. 02).

En un artículo reciente hemos analizado el origen y la gestión de los equipamientos religiosos en el polígono de Coya durante los años sesenta y setenta, poniéndolos en relación con la evolución y desarrollo del concepto de dotación urbanística o "edificación complementaria $»^{2}$. Detengámonos ahora en el comentario de estos cuatro edificios, inéditos hasta la fecha, y en las vicisitudes por las que pasó cada uno de ellos hasta su configuración actual. Sus peripecias - si es que cabe denominarlas así- muestran las dificultades que tuvieron los distintos actores en la Espańa del momento para llevar a cabo proyectos eminentemente comunitarios como estos.

\section{SAN MARTÍN DE COYA (1969/81)}

La historia de la parroquia de San Martín de Coya, cuya sede era una pequeńa iglesia barroca de un sólo cuerpo, se remonta al siglo XVI.

En 1953 el arquitecto Antonio de Cominges Tapias recibió el encargo de redactar un nuevo proyecto ${ }^{3}$. Cominges estaba trabajando en la capilla del colegio de los padres jesuitas Santiago Apóstol $(1951 / 54)^{4}$, y posteriormente realizaría otras iglesias importantes en la ciudad, como las de Nuestra Señora del Carmen (1957), La Soledad (1957) o Nuestra Señora de Fátima (1959). La construcción del nuevo edificio - que dejaba dentro de su planta la antigua iglesia - comenzó en 1955. Sin embargo, tras la aprobación en 1961 de la nueva ordenación del polígono de Coya, el proyecto tuvo que paralizarse, y buena parte de su cerramiento pétreo que ya se había levantado, tuvo que ser demolido (Fig. 03).

En 1969, el obispo fray José López Ortiz aprobó los planos del nuevo templo, proyectado por Arturo Fraga Framil (Vigo, 1916, t. 1942) 5 . Su presupuesto se había rebajado de modo considerable, y la construcción que no comenzó hasta 1973 - fue muy lenta, debido a las dificultades de todo tipo que aparecieron durante 

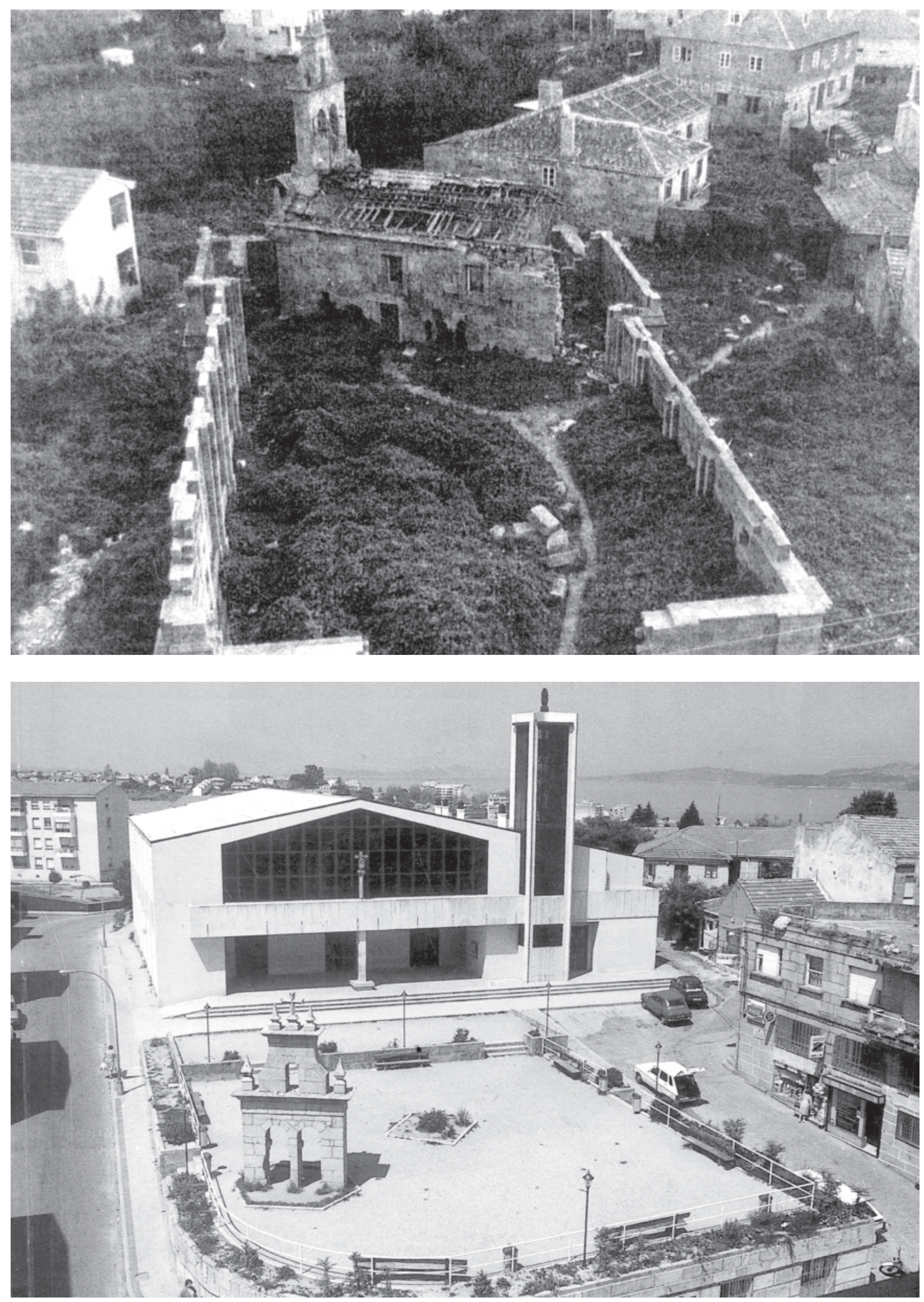

3 La iglesia barroca de San Martín de Coya, insertada dentro de los muros del primer proyecto a medio construir (h. 1962) 4 Arturo Fraga Framil, la iglesia parroquial de San Martín de Coya el dia de su inauguración (1981) 

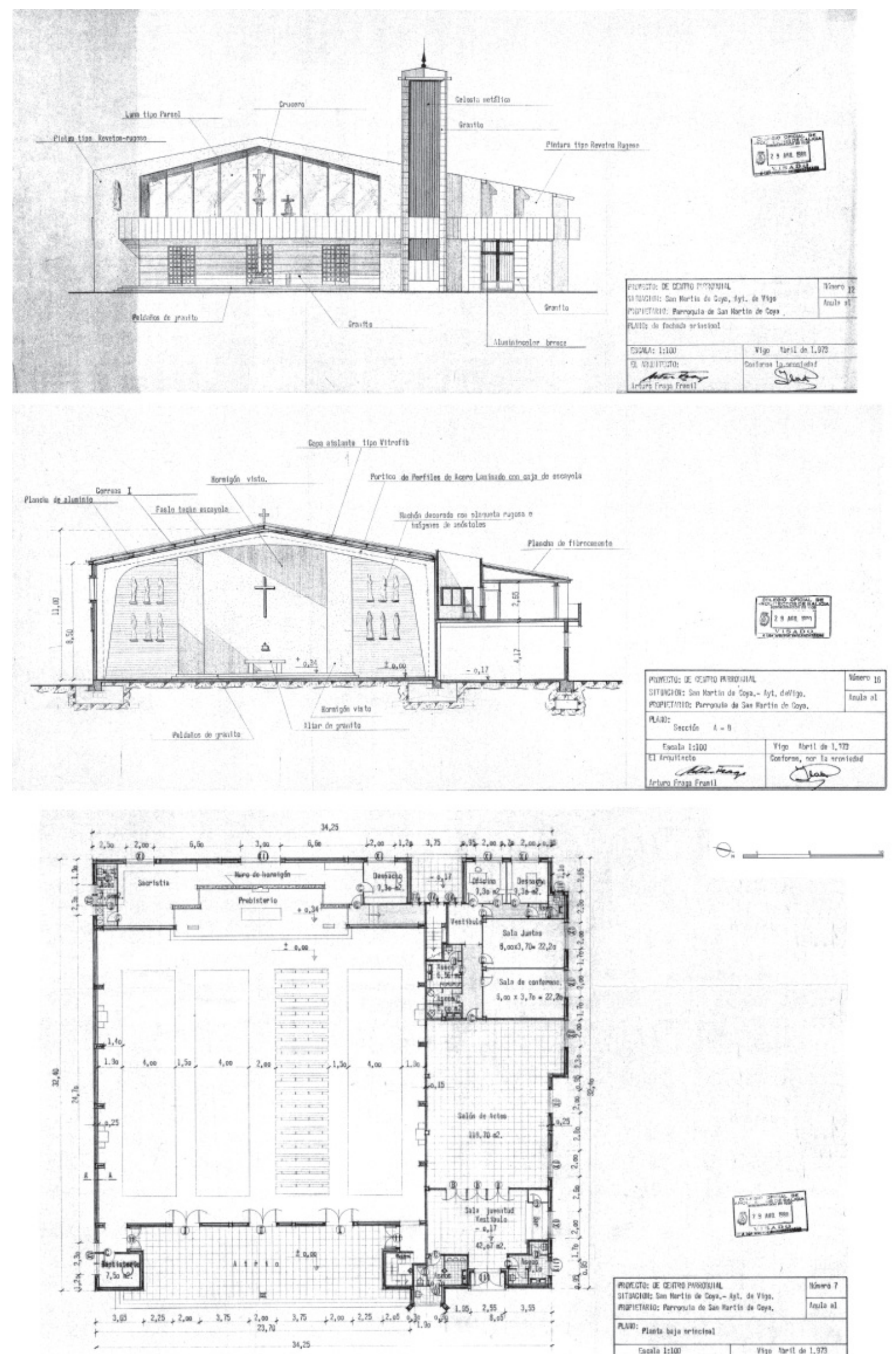

$\theta$

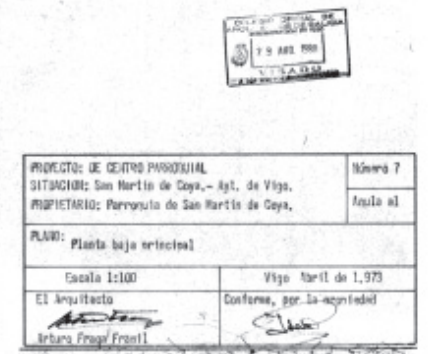

5 Arturo Fraga Framil, San Martín de Coya (Vigo, 1969/81)

18 | Boletín Académico 3 (2013) 

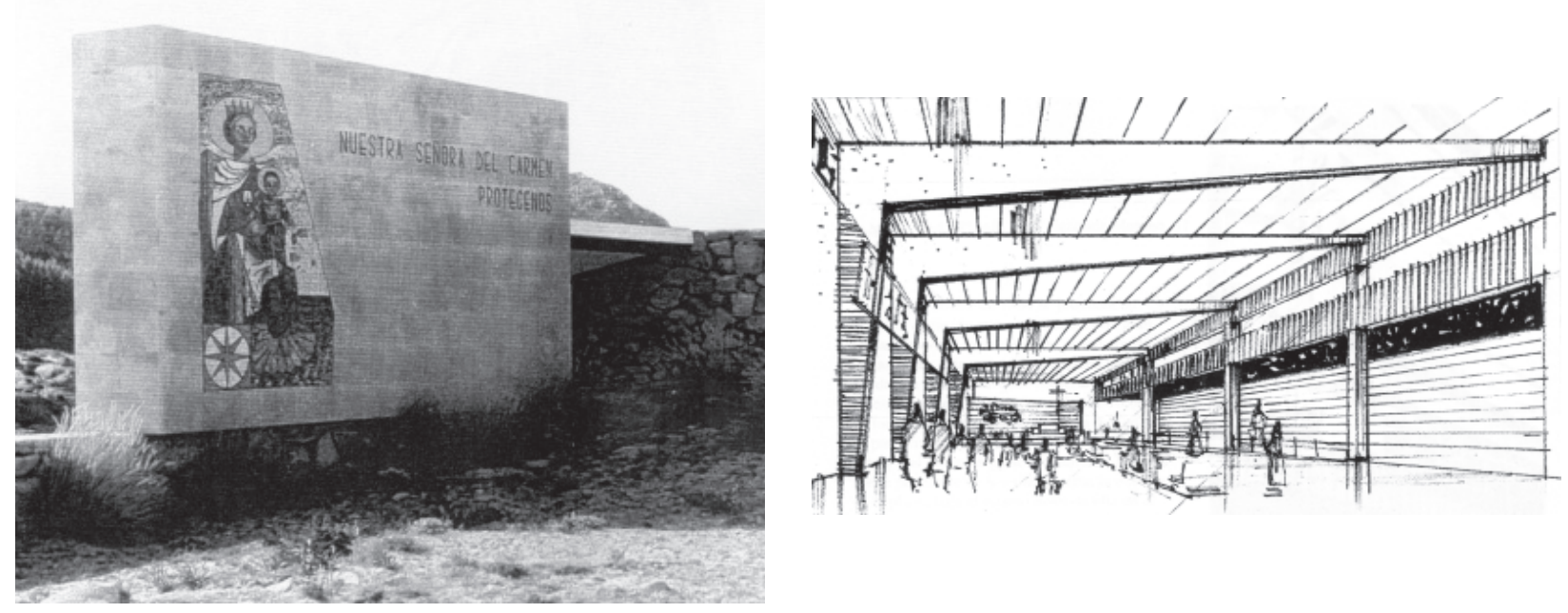

6 Tomás Pérez-Lorente Quirós y Francisco Yáñez Ulloa, capilla abierta dedicada a Nuestra Señora del Carmen en las islas Cíes (1962) 7 Tomás Pérez-Lorente Quirós y Francisco Yáñez Ulloa, edificio de Obras Sociales para los padres jesuitas (Vigo, 1964)

los años siguientes: la obtención de subvenciones, las permutas de terrenos y la intervención de múltiples intereses y organismos ${ }^{6}$. Mientras tanto, la comunidad parroquial celebraba el culto en el bajo de una vivienda. En 1980 el centro parroquial obtuvo la licencia municipal, y tras muchos avatares, se inauguró el 12 de octubre de 1981 (Fig. 04). La promoción de la obra corrió a cargo del Instituto Nacional de la Vivienda.

La parte más reseñable del proyecto era la estructura, conformada por seis pórticos metálicos que salvaban una luz de $24,30 \mathrm{~m}$. y alcanzaban una altura de 10,80 m., dándole al interior una notable potencia expresiva. Pero durante la ejecución de la obra esta estructura se ocultó, de tal modo que la nave cubierta a dos aguas acabó presentando un interior absolutamente neutro. Este no fue el único cambio. Cualquiera que visite la iglesia tras haber estudiado los planos podrá comprobar que los diversos elementos ornamentales que en la actualidad decoran el muro que se encuentra tras el altar, no se corresponden en absoluto con el terso paño de hormigón visto sobre el que se preveía la colocación de un sencillo crucifijo, flanqueado por un grupo de seis apóstoles de gran tamaño.

Así, el centro parroquial de San Martín de Coya - la parroquia matriz del polígono- es hoy un edificio extremadamente sencillo, que además de la iglesia, incluye algunas dependencias parroquiales y dos viviendas (Fig. 05). Se encuentra situado al fondo de una plaza elevada sobre las calles circundantes, cuya traza está vinculada con el tejido rururbano exterior a la trama del polígono. Es ésta su característica más singular y la más interesante desde el punto de vista urbanístico. En la plaza se colocó la espadaña de la antigua iglesia, mientras que el crucero ahora preside la fachada principal; estos dos elementos guardan la memoria de lo que antańo fue el centro de la vida de un territorio rural.

\section{NUESTRA SEÑORA DEL PERPETUO SOCORRO (1967/70)}

La iglesia de Nuestra Señora del Perpetuo Socorro se ubica en el extremo norte del polígono de Coya, muy cerca de la plaza de Las Traviesas, y fue encomendada desde el principio a los padres redentoristas.

El proyecto corrió a cargo de los arquitectos Francisco Yáñez Ulloa (Vigo, 1924, t. 1957) y Tomás PérezLorente Quirós (Vigo, 1926-2006, t. 1957), que ya tenían experiencia en arquitectura religiosa. En 1962 habían realizado una pequeña capilla abierta en las islas Cíes dedicada a la Virgen del Carmen, un espacio rectangular formado dos muros, uno de los cuales servía como soporte a un gran mosaico mariano ejecutado en la escuela del monasterio de Poio ${ }^{7}$ (Fig. 06).

En 1964 los mismos arquitectos habían construido el edificio de Obras Sociales de los padres jesuitas en Vigo, cuya atrevida propuesta estructural incluía unas vigas de celosía de quince metros de altura que descargaban en jácenas de hormigón armado de sección variable situadas sobre el espacio de la iglesia, logrando un espacio de culto diáfano y elegante (Fig. 07). Los elementos ornamentales y el mobiliario de esta igle- 

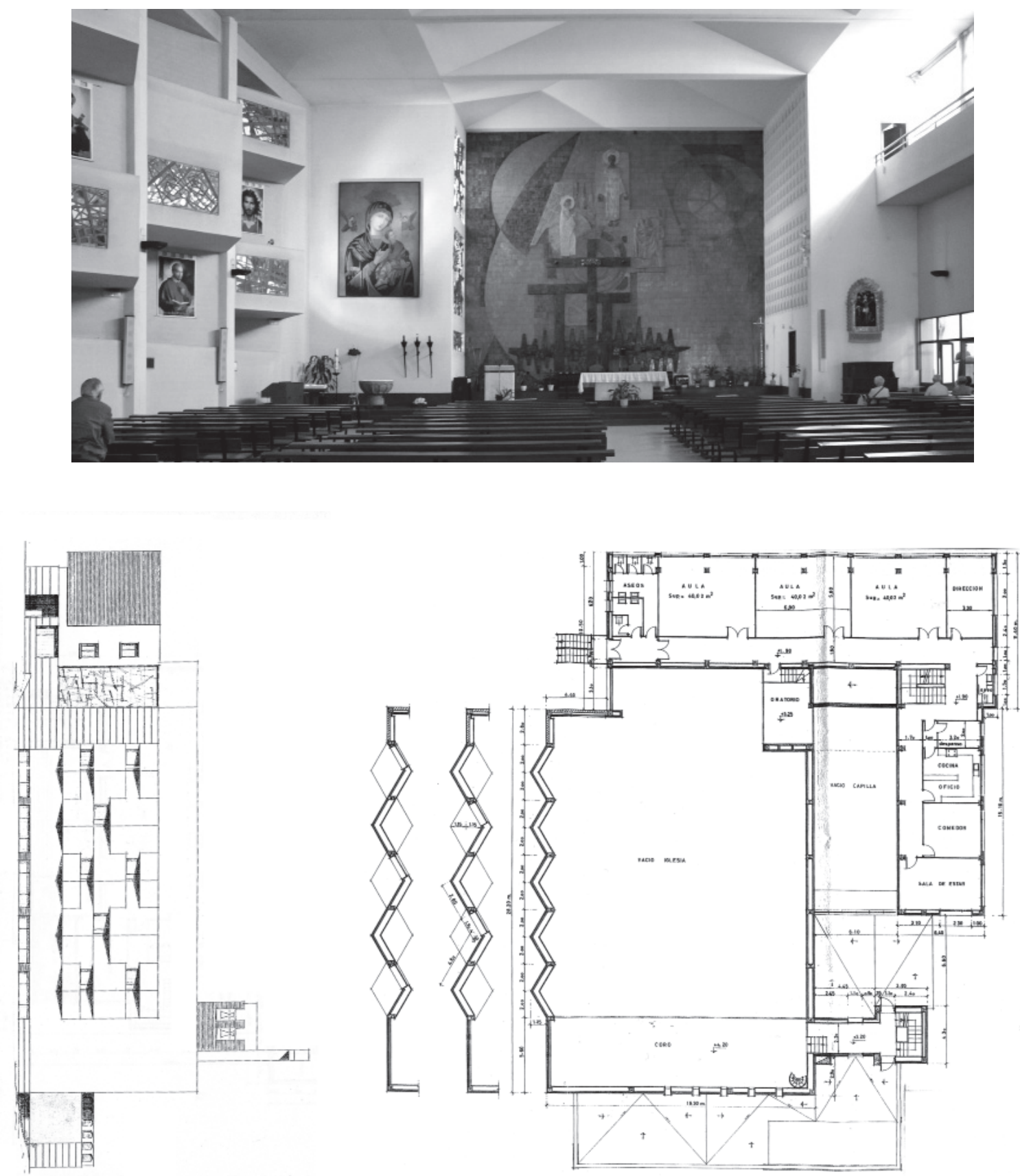

Ptanta primusa

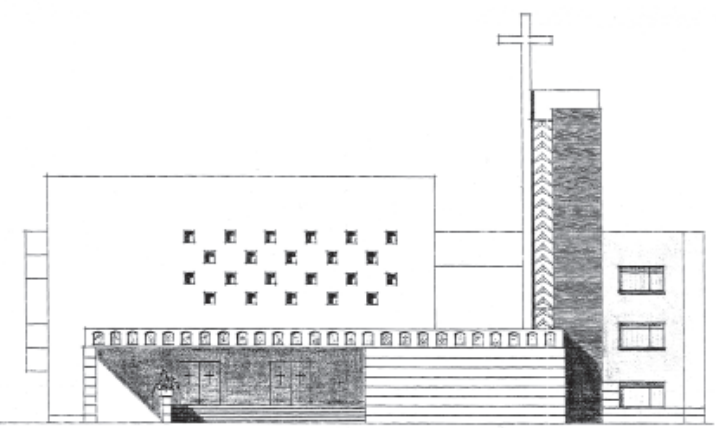

8-9 Tomás Pérez-Lorente Quirós y Francisco Yáñez Ulloa, Nuestra Señora del Perpetuo Socorro (Vigo, 1967/70); interior de la nave y planos 20 | Boletín Académico 3 (2013) 


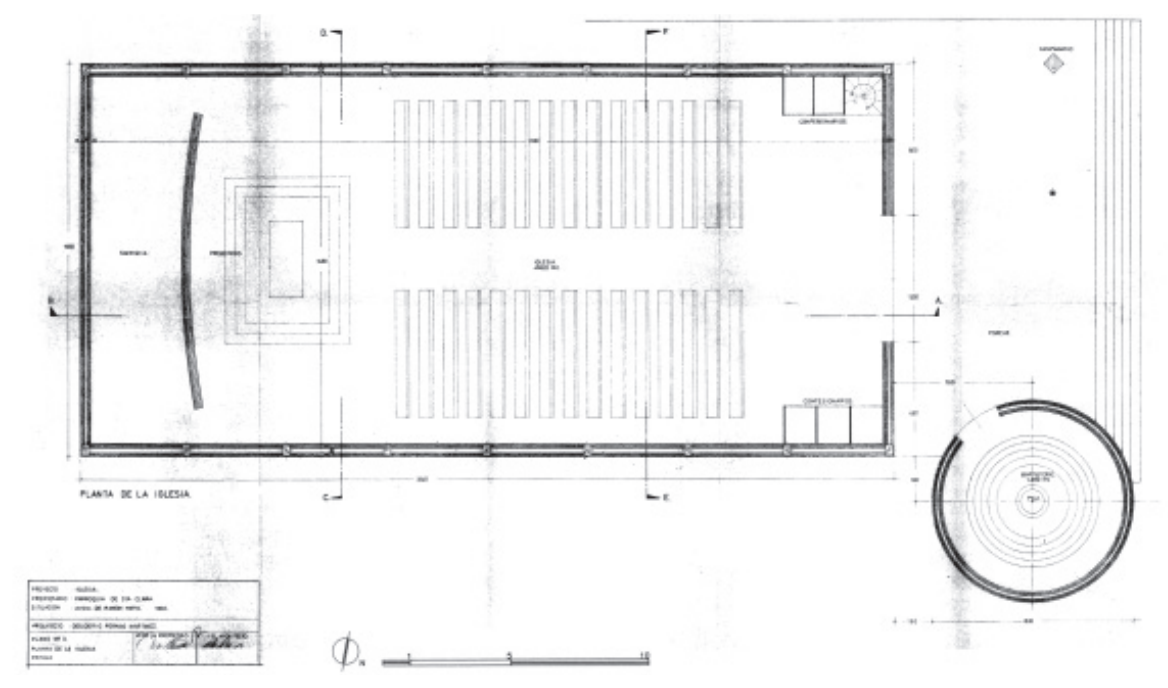

10 Desiderio Pernas Martínez, Santa Clara Nigo, 1968); planta

sia fueron diseñados en colaboración con el escultor Xoán Piñeiro Nogueira.

Con estos precedentes, es natural que la iglesia del Perpetuo Socorro sea un edificio que destaque por sus líneas puras y su luminoso espacio interior (Fig. 08-09). Podría describirse como una caja blanca enriquecida con un gran retablo cerámico de corte abstracto, que narra la resurrección (otros opinan que es la ascensión) de Jesucristo. Varias vidrieras dispuestas sobre un muro quebrado aportan un contrapunto de color. Todas estas piezas fueron diseñadas por el padre redentorista Carlos Pereira Prado.

La exacta disposición del mobiliario litúrgico revela el interés de los arquitectos por seguir las disposiciones del Concilio Vaticano II8. De hecho, durante su época de estudiantes en Madrid habían participado en un seminario organizado por Víctor D’Ors, donde tuvieron la oportunidad de escuchar al padre Alfonso Roig Izquierdo? Siguiendo sus recomendaciones, aquí intentarán aplicar los conceptos de religiosidad, veracidad y autenticidad:

La religiosidad, construyendo una obra de arte que proporcione una emoción religiosa superior a la artística, facilitando a los fieles la comunicación con Dios. La veracidad, utilizando las formas plásticas consecuencia de las nuevas técnicas, de manera que tengan valor por sí mismas, sin recurrir a la mentira de las decoraciones superpuestas; y la autenticidad, siguiendo las enseñanzas de una tradición bien entendida, haciendo una arquitectura concordante con el modo de sentir de la época en que vivimos ${ }^{10}$.
El edificio no está orientado canónicamente hacia el este, y su relación con la ciudad es confusa. Aunque la entrada natural a la iglesia hubiera sido desde el paseo superior, el notable desnivel del terreno aconsejó girarla hacia la calle Lalín, donde aparece una pequeña plaza y un pórtico cubierto. Desde allí se ingresa a la nave central y al baptisterio, así como a las demás dependencias, situadas en el semisótano.

El proyecto fue ejecutado con algunas variaciones con respecto a la propuesta inicial ${ }^{11}$. Por ejemplo, la abundante iconografía mariana que adornaba la viga de cintura que cerraba el porche se eliminó, así como las imágenes de Cristo y San Juan Bautista, parcialmente sumergidas en un estanque vinculado al baptisterio, que tampoco se llegaron a realizar. Ni siquiera se ejecutó la torre de la iglesia - compuesta por dos diedros de hormigón enlazados- y en su lugar se colocó una sencilla cruz conformada con dos perfiles de acero.

A pesar de todo, el interés del edificio no se ha resentido en exceso, gracias al acertado uso que los arquitectos hicieron de la luz natural y del color.

\section{LA VIRGEN DEL ROCÍO (1973/77)}

El centro parroquial de la Virgen del Rocío se podría poner como ejemplo de cómo las limitaciones económicas pueden ahogar una arquitectura del máximo interés y dejarla prácticamente irreconocible.

Segregada de Bouzas y de San Martín de Coya en 1970, como ya hemos dicho, la parroquia comenzó 

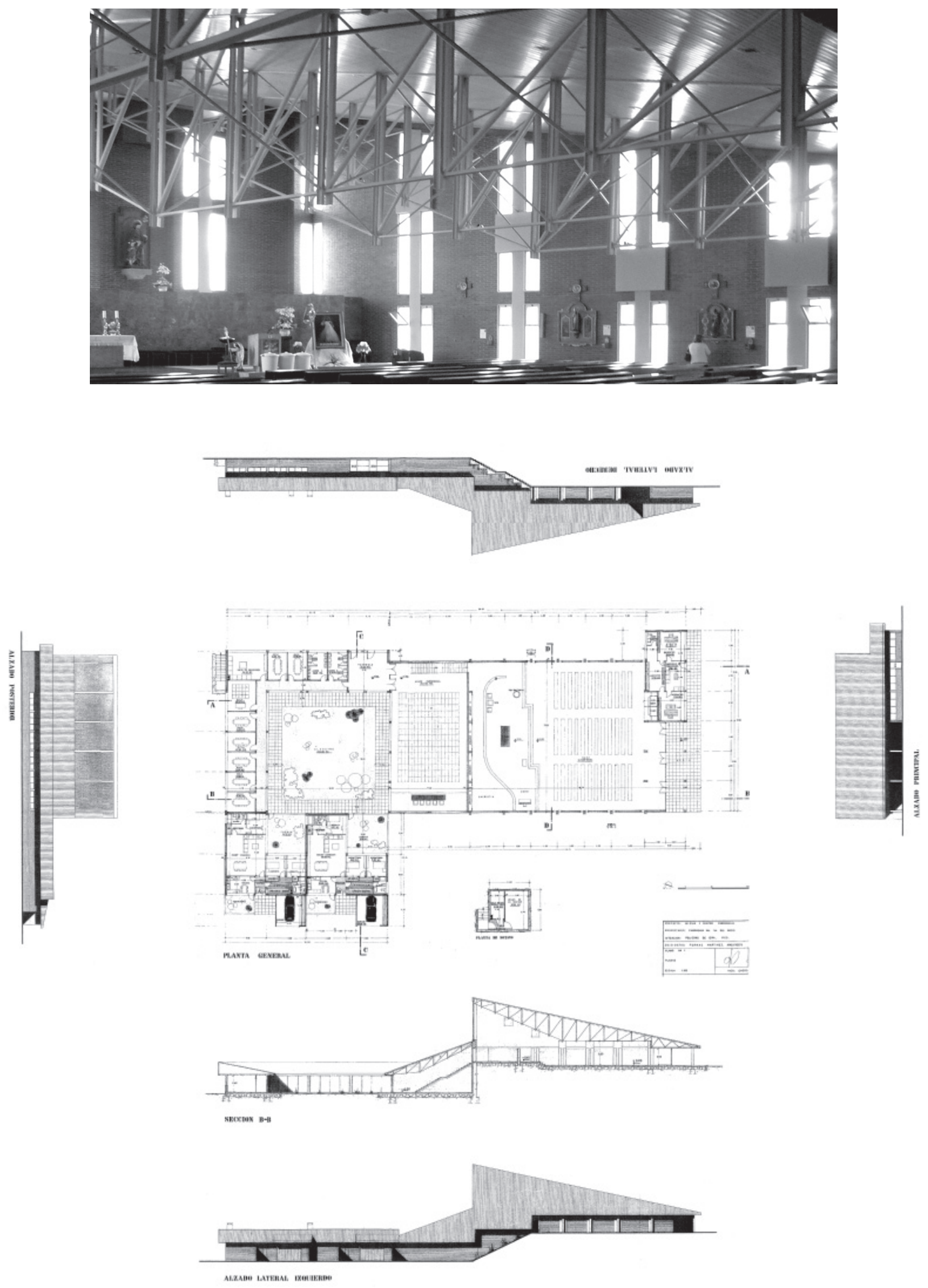

11-12 Desiderio Pernas Martínez, La Virgen del Rocío (Vigo, 1973/77); interior de la nave y planos

22 | Boletín Académico 3 (2013) 

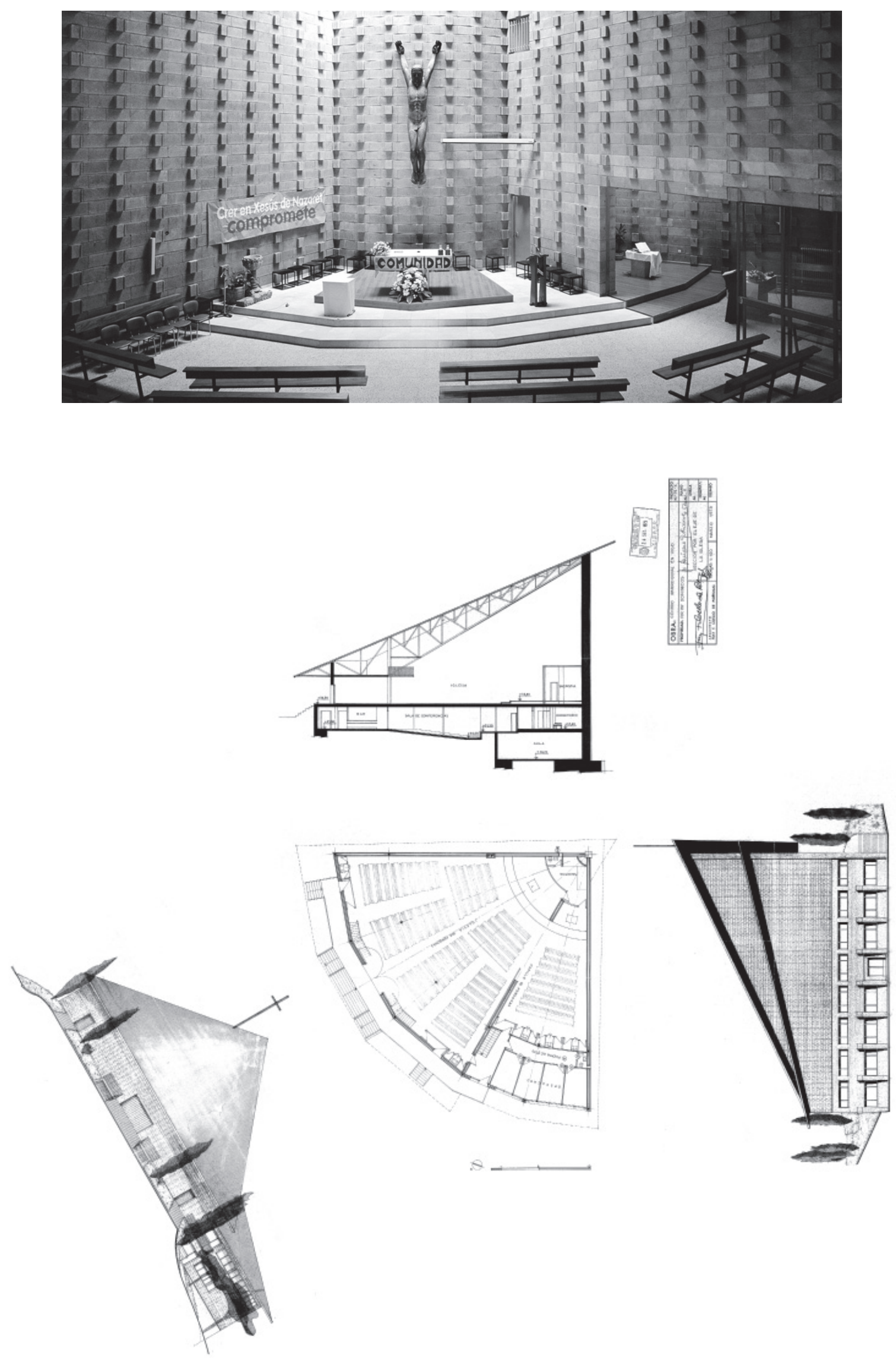

13-14 Francisco Coello de Portugal Acuña OP, Santísimo Cristo de la Victoria (Vigo, 1973/81); interior de la nave y planos 

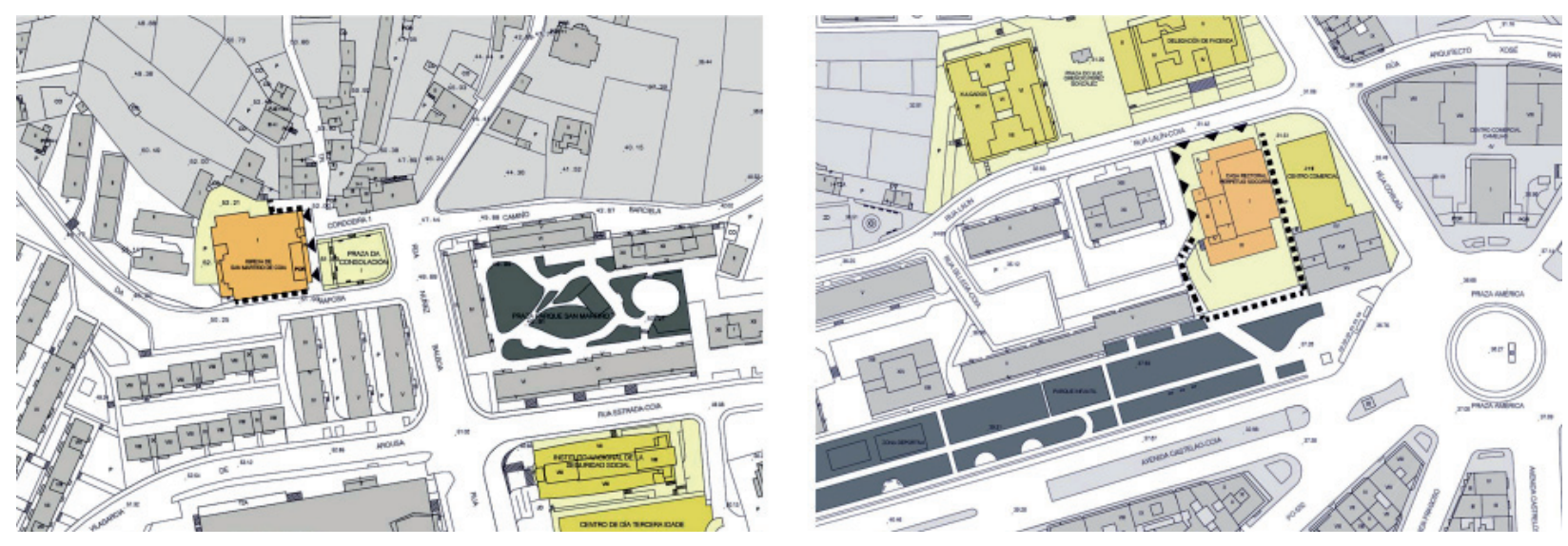

15 Relación de los cuatro centros parroquiales con la trama urbana más próxima: San Martín de Coya, Nuestra Señora del Perpetuo Socorro, La Virgen del Rocío y Santísimo Cristo de la Victoria.

su actividad en los bajos de una vivienda, mientras se realizaban los trámites para adquirir el solar de casi $3.600 \mathrm{~m} 2$. que hoy ocupa, a través de un acuerdo con el Ministerio de la Vivienda y la Caja de Ahorros Municipal de Vigo. La construcción de la iglesia fue sufragada por contribuciones particulares, donaciones e incluso participaciones en forma de compra simbólica de metros cuadrados de construcción ${ }^{12}$.

El proyecto fue redactado por Desiderio Pernas Martínez (Vigo, 1930/96, t. 1958), en aquel momento el arquitecto vigués por antonomasia. Pernas había sido alumno de Mies van der Rohe en el IIT de Chicago, y se puede decir que la aplicación del magisterio del maestro alemán — claridad de ideas, sencillez constructiva y un lenguaje muy depurado- marcó el carácter del polígono de Coya ${ }^{13}$.

Pernas ya había construido la iglesia de Santa Clara (Vigo, 1968), en la que exploraba el potencial de los recursos escasos y los materiales vistos. Elegante en su simplicidad, presenta una planta pautada por un doble orden de pórticos de hormigón (Fig. 10). La delicada transición entre el interior y el exterior se consigue al minimizar la altura del atrio. El baptisterio - de planta circular - y una cruz construida con un poste eléctrico prefabricado, completan el conjunto.

Algunos de estos recursos también se utilizarán en el Rocío, cuyo proyecto original era inequívocamente aaltiano (Fig. 11). Una gran cubierta quebrada a dos aguas caracteriza el conjunto: la parte que da al paseo —que fue lo único que se construyó- acoge la igle- sia, mientras que el cuerpo posterior incluía un salón parroquial, diversas aulas y dos viviendas, distribuidas alrededor de un amplio patio porticado.

En la actualidad, es difícil hacerse cargo de la composición volumétrica del conjunto. Sólo desde el interior del templo se puede intuir todavía hoy lo que pudo llegar a ser el edificio. El espacio de culto queda marcado por unas cerchas metálicas vistas que van levantando la cubierta desde el atrio exterior, de muy baja altura, mientras que su cordón inferior dibuja un plano virtual que mantiene el espacio en una escala humana (Fig. 12). La iluminación lateral es confusa, ya que la iglesia está orientada a norte, mientras que la plementería vista de ladrillo — nada corriente en Galicia- le da al edificio un carácter aún más exótico.

Muchos años después, Desiderio Pernas retomó el programa religioso con el centro parroquial de Santa Eulalia de Alcabre (1993), un ejercicio de construcción neotradicional donde el arquitecto amplió homotéticamente la antigua iglesia, espadaña barroca incluida. A pesar de todo, gracias a su oficio logró conseguir un ambiente sereno y respetuoso con el culto, en una arquitectura muy distinta a la desplegada en Coya durante las décadas de los años sesenta y setenta, y que acaso merecería un análisis más sosegado ${ }^{14}$.

\section{SANTÍSIMO CRISTO DE LA VICTORIA $(1973 / 81)$}

Dejando aparte el hecho de ser la ultima de las iglesias construidas en Coya, lo que singulariza al Santísimo 


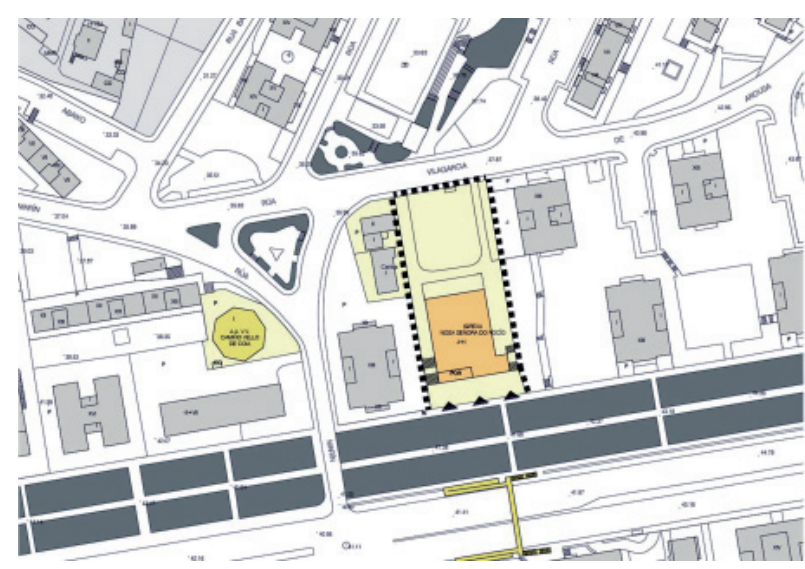

Cristo de la Victoria con respecto a las otras tres iglesias del polígono es su arquitecto, Francisco Coello de Portugal Acuña (Jaén, 1926, t. 1953). Coello es un reconocido especialista en arquitectura religiosa, hasta el punto de que ha sido el arquitecto español más prolífico en este campo durante el siglo $\mathrm{XX}^{15}$. Tras ingresar en la orden de los dominicos en 1955, su trayectoria profesional se inició con el proyecto del santuario, convento y colegio apostólico de la Virgen del Camino en León (1957/61), y se prolonga en la actualidad.

Esta iglesia forma parte de una serie de edificios coetáneos que incluye, entre otros, varias capillas escolares construidas en las islas Canarias y el centro parroquial Santo Domingo en Burgos (1971/73). La iglesia de Coya muestra mucho parecido con ellos, tanto en su distribución espacial como en las técnicas constructivas y en los materiales utilizados (Fig. 13).

El edificio se implanta en el barrio como un hito urbano. $\mathrm{Su}$ aspecto exterior posee una contundencia formal capaz de competir con los enormes edificios de viviendas de su entorno. Y sin embargo, el acceso frontal un voladizo envolvente- es blando en escala, y proporciona una aproximación suave desde la calle y el jardín.

El interior golpea los sentidos por la inesperada combinación de rudeza y refinamiento. La intensa luz que baña el fondo del presbiterio, los toscos aparejos de bloque de hormigón visto, y la forma en sector circular de la nave con el altar situado en el vértice, constituyen los invariantes formales con los que Coello trabaja, demostrando la versatilidad de su esquema (Fig. 14).

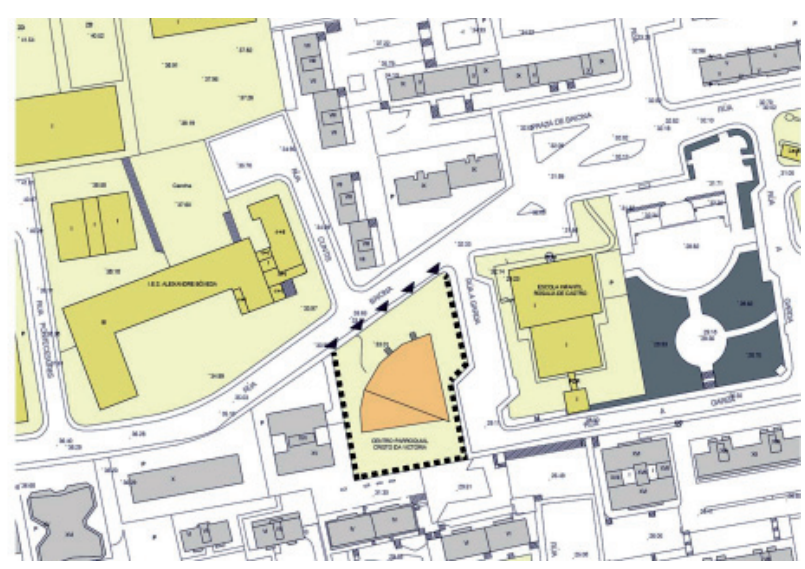

Es fácil percibir la seguridad en el trazado que tiene esta iglesia en comparación con los otros tres ejemplos estudiados, o incluso el cierto desinterés que irradia. Entendámonos bien: se ve que el autor disfruta haciendo arquitectura (el espacio está controlado y cuidado), pero no pretende hacer aquí la obra de su vida; simplemente adapta un esquema que ya tiene muy estudiado a las condiciones específicas del sitio y del cliente, en este caso, los padres dominicos ${ }^{16}$. Además, es la única de las cuatro que está orientada canónicamente, lo que facilita una correcta percepción del espacio de culto.

Coello llevará su obra a extremos de virtuosismo, exprimiendo al máximo la debatida cuestión de la austeridad, entendida tanto desde las necesidades económicas reales como desde una nueva sensibilidad más implicada con el papel social de la arquitectura ${ }^{17}$. De hecho, esta parroquia ha sido, desde su inicio, un foco muy activo de reivindicaciones vecinales.

\section{DIMENSIÓN URBANA DE LOS CENTROS PARROQUIALES}

Digamos, por último, una palabra acerca de la relación de estos edificios con el polígono en el que se inscriben. Durante los años en los que se construyó el polígono de Coya, los edificios parroquiales —además de ser centros de culto- pasaron a ser verdaderos centros de actividad administrativa y social, vocación reafirmada por el interés de la Iglesia Católica en desempeñar un papel en la formación integral y en la asistencia a sus fieles. En nuestro caso, su carácter de edi- 


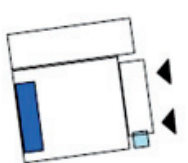

San Martín

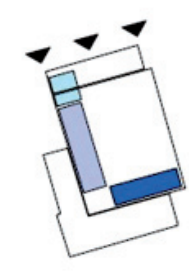

Perpetuo Socorro

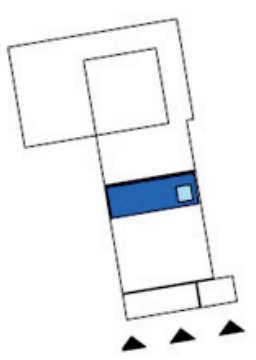

Rocío
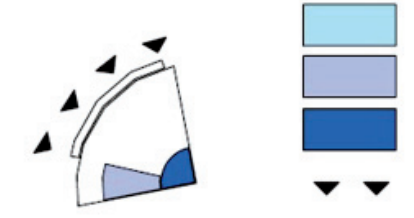

baptisterio

capilla reserva

presbiterio

acceso

Cristo de la Victoria

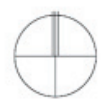

16 Esquemas de funcionamiento interno de los cuatro centros parroquiales

ficios de usos múltiples se tradujo en una relación con el espacio público que les permite absorber grandes flujos de personas, y en la segregación de sus accesos. Los mecanismos utilizados para favorecer esta relación fueron diferentes según los casos (Fig. 15).

En San Martín de Coya, el acceso frontal se resuelve mediante un pequeño desnivel escalonado sobre una plaza peatonal desde el que se accede al atrio cubierto y al centro parroquial; la parte posterior de la parcela se reserva para uso privado.

En el Perpetuo Socorro, el edificio se retranquea con respecto a la calle y la transición al interior se resuelve a través de una escalinata que forma parte del atrio; los accesos a las dependencias parroquiales se colocan en el lateral del edificio y la parte trasera de la parcela se reserva para el uso de la comunidad residente.

En el caso de la Virgen del Rocío, la relación con el entorno aparece alterada por la construcción parcial del edificio, lo que origina una trasera ciega al espacio libre de la parcela que no hubiera existido de completarse la edificación según el proyecto inicial, que hubiera resuelto el acceso al centro parroquial desde la calle posterior.

Finalmente, en el Santísimo Cristo de la Victoria, la conexión con el barrio se produce a través de un espacio de transición ajardinado, desde el que se accede al pórtico de entrada o bien a las plantas inferiores del edificio en la que se encuentran las dependencias parroquiales.
El peso de la implantación de los centros parroquiales en el polígono llegó hasta el punto de condicionar completamente su organización interna, algo impensable en las iglesias sólo algunos años atrás. Los cuatro edificios ubican las dependencias auxiliares (no cultuales) en función de las características urbanísticas de las parcelas: posibilidades de acceso, topografía o posición respecto a los viales. Así, el Perpetuo Socorro y San Martín tienen estas dependencias en posición lateral (envolvente) respecto a la nave, y el Santísimo Cristo de la Victoria y la Virgen del Rocío en las plantas inferiores, siempre permitiendo el uso independiente de ambos usos (Fig. 16).

Esta solución, determinada por el hecho urbano, se traslada incluso a la organización de los espacios litúrgicos donde, lejos de prevalecer normas o sugerencias canónicas, el conjunto se subordina a la correcta inserción del edificio con las condiciones de cada parcela en particular. Lo mismo ocurre con los elementos identificativos e identitarios, como cruces o campanarios. Como se ve, el simbolismo litúrgico y cosmológico del templo cristiano, tal como se venía entendiendo hasta el momento, pasaba por sus horas más bajas ${ }^{18}$.

Conviene volver a recordar que todos los edificios sufrieron largos procesos de tramitación burocrática y dificultades en la obtención de recursos, que contribuyeron a que su construcción se prolongara en el tiempo. De hecho, el Santísimo Cristo de la Victoria es el único de los cuatro que fue construido siguiendo fielmente el proyecto (Fig. 17). 

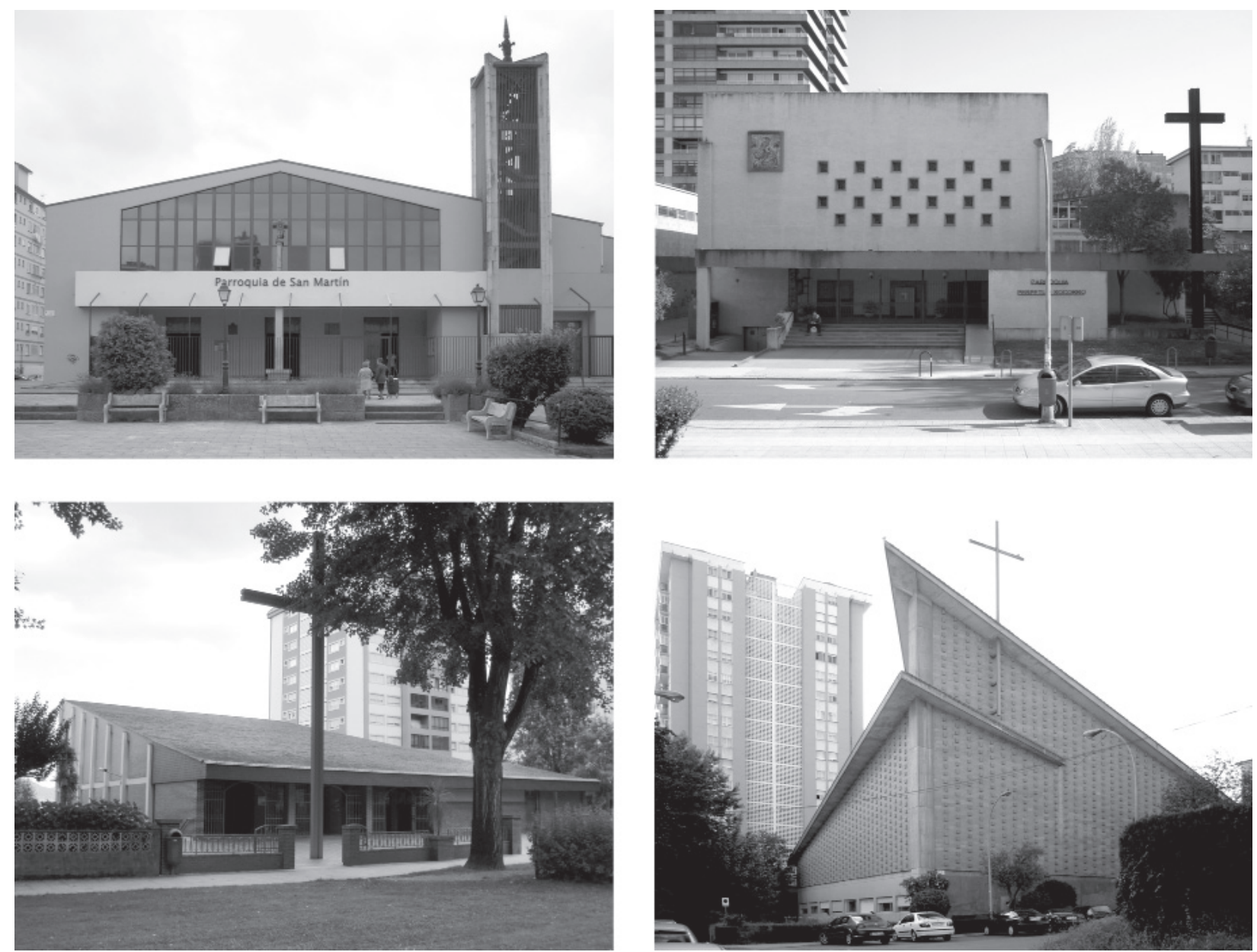

17 Aspecto exterior de los cuatro centros parroquiales en la actualidad: San Martín de Coya, Nuestra Señora del Perpetuo Socorro, La Virgen del Rocío y Santísimo Cristo de la Victoria

Además, a lo largo de los últimos años estas relaciones con el espacio público planteadas por los autores se han visto modificadas por las actuaciones de delimitación y acotación de las parcelas mediante cierres perimetrales. Durante la reconversión industrial de los años ochenta, Vigo se convirtió en una de las ciudades más conflictivas de España, y Coya en uno de sus barrios más peligrosos. Y así, por motivos de seguridad, unos edificios abiertos que deberían funcionar en continuidad con los espacios públicos aparecen en nuestros días separados de ellos, interrumpiendo así las transiciones planteadas.

Con todo, se puede decir que durante los ańos sesenta y setenta el programa religioso todavía era —al menos teóricamente- una oportunidad para el despliegue de arquitectura de calidad, siempre que las condiciones de partida no se alterasen, como ocurrió en el caso concreto de los centros parroquiales del polígono de Coya en Vigo. 
1. Cf. Ramón Rodríguez Otero, San Martín de Coia. La larga marcha de una comunidad (Vigo: Parroquia de San Martín, 1998). En 1982 se reajustaron de nuevo los límites de varias parroquias.

2. Cf. Esteban Fernández-Cobián y Marta Vilas Rodríguez, "Los equipamientos religiosos como configuradores del espacio urbano. El caso del polígono de Coya en Vigo (España)», Dearq 11 (2012): artículo aceptado.

3. Cf. AHMV (781/31).

4. Desde 1970 es iglesia parroquial.

5. Arturo Fraga Framil colaboró con Luis Gutiérrez Soto, primero en Madrid como estudiante y a partir de 1946 en Vigo, como arquitecto colaborador en la obra del Cine Fraga. Con los edificios de viviendas en la calle García Barbón 50-52 (1958) y Gran Vía 146 (1959), el edificio La gafa de oro en la calle Policarpo Sanz 32, y varios novedosos edificios de apartamentos, todos en Vigo, Fraga realiza una renovación del lenguaje arquitectónico local apoyado en un innovador uso de la piedra y en sus combinaciones con otros materiales. Esta estética la compartirá con otros arquitectos de ese periodo que algunos han llegado a denominar estilo vigués.

6. Cf. Rodríguez Otero, San Martín de Coia, 43.

7. Lamentablemente, el edificio fue abandonado y en 1993 se demolió lo que quedaba de él, restaurándose sólo parte del mosaico. Una somera descripción de las obras se puede leer en la placa de bronce que el ayuntamiento colocó en el muro de la capilla.

8. Cf. Tomás Pérez-Lorente Quirós, La obra arquitectónica de Tomás Pérez-Lorente Quirós y Francisco Yánez Ulloa. Doctores arquitectos (Vigo: Pro-manuscripto, 1998); el original se conserva en el archivo de la Delegación en Vigo del COAG. En él aparece una copia de una reseña de prensa, sin fecha, sobre la conferencia "Arquitectura religiosa", pronunciada con motivo de una exposición de Arte Sacro en Vigo.

9. Sacerdote, profesor, escritor y crítico de arte, entre su obra se encuentran los textos El arte de hoy y la Iglesia (1954), La pintura religiosa de Georges Rouault (1959) o Diálogo de la Iglesia con el mundo moderno de la Arquitectura (1964).

10. Pérez-Lorente, La obra arquitectónica. Este documento está sin paginar.

11. El centro parroquial obtuvo licencia municipal el 27 de diciembre de 1967.

12. En una entrevista a la prensa, el párroco afirmaba que la primera entidad que ayudó en este sentido fue el FC Barcelona (cf. Sa. «40 aniversario de parroquia y cura», www.farodevigo.es/gran-vigo/2010/11/20/40-aniversario-parroquia-cura/492883.html; con acceso 10/09/2012).

13. Pernas fue el autor de un $53 \%$ de la superficie construida total del polígono de Coya (cf. Souto González, Vigo. Cen anos, 522-532).

14. Significativamente, la exposición-homenaje realizada en el Centro Cultural Caixanova de Vigo en 2005 no llega hasta este periodo, y el catálogo inédito que realiza Ronald Baer Fokker, a pesar de contar con la participación de colaboradores y allegados, tampoco aborda esta cuestión. Cf. Ronald Baer Fokker, Desiderio Pernas Martínez (1930-1996) (Vigo: Pro-manuscripto, 2006), el original se conserva en la biblioteca de la Delegación en Vigo del COAG; Perfecto Cendón Domínguez, Javier Vázquez Fernández y Andrés Touceda Gómez, Desiderio Pernas do detalle á cidade: 60/70, Catálogo de la exposición, Centro Cultural Caixanova, 9 de septiembre/18 de octubre de 2005 (Vigo: Caixanova, 2005).

15. Sobre el alcance de la obra de Coello puede verse, por ejemplo, Esteban Fernández-Cobián, Fray Coello de Portugal. Dominico y arquitecto (Madrid: Fundación Antonio Camuñas/San Esteban, 2001); Francisco Coello de Portugal Acuńa, La arquitectura, un espacio para el hombre (Pamplona: T6, 2005); José Manuel Pozo Municio, Fray F. Coello de Portugal. Santuario de la Virgen de Camino (Pamplona: T6, 2006); Rubén Labiano Novoa, "Fray Coello de Portugal, viajes sin cuaderno", en Varios autores, Viajes en la transición de la arquitectura española hacia la modernidad (Pamplona: T6, 2010): 207-216; Idem., "Fray Coello de Portugal y las revistas de arte sacro: una relación indirecta», en Varios autores, Las revistas de arquitectura (19001975): crónicas, manifiestos, propaganda (Pamplona: T6, 2012): 605-614.

16. En 1979, la traza circular de la fachada del proyecto inicial de 1973 se convirtió en poligonal; el resto del edificio quedó prácticamente igual. De hecho, no se redibujaron los alzados.

17. Al comienzo de la memoria del proyecto, Coello explica que la iglesia «se proyecta con la capacidad necesaria, pero con un espíritu de austeridad y economía, tanto por la falta de medios como por criterio de los promotores, en conformidad con la mentalidad y disposiciones postconciliares de la Iglesia» (Fray Francisco Coello de Portugal Acuña OP, «Proyecto de centro parroquial en Vigo, propiedad de los PP. Dominicos» (1973), Archivo de la parroquia del Santísimo Cristo de la Victoria (Vigo), 1. Sobre este tema también puede verse Esteban Fernández-Cobián, «Fray Coello de Portugal y el debate sobre la pobreza en la arquitectura religiosa durante la segunda mitad del siglo XX", Arquiteturarevista 7 (2011): 112-125 (doi: 10.4013/ arq.2011.72.03).

18. Cf. Jean Hani, El simbolismo del templo cristiano (Palma de Mallorca: Sophia Perennis, 2008 [1962]).

\section{Procedencia de las ilustraciones}

Fig. 01, 08, 10, 12 y 17. Archivo de los autores.

Fig. 02. Elaboración propia a partir del planeamiento de 1975.

Fig. 03-04. Rodríguez Otero (1998).

Fig. 05. AHMV 7808/80.

Fig. 06-07. Archivo del estudio Yáñez \& Pérez-Lorente.

Fig. 09. Elaboración propia sobre material del AHMV (E-7685/67).

Fig. 11. Elaboración propia sobre material del AHMV (E-1660/73).

Fig. 13. Elaboración propia sobre material del archivo de la parroquia del Santísimo Cristo de la Victoria.

Fig. 14. Archivo de los autores (Vari Caramés).

Fig. 15. Elaboración propia sobre cartografía del PXOM 2008/09 de Vigo.

Fig. 16. Elaboración propia.

\section{Sobre los autores}

Marta Vilas Rodríguez (Vigo, 1965), Arquitecto por la ETSA A Coruńa (1992), obtuvo el Diploma de Estudios Avanzados en el departamento de Representación y Teoría Arquitectónica de la ETSAC (2011). Desarrolla su actividad profesional en Vilas Puente Arquitectos, Vigo (var7.blogspot.com.es).

martavilas@coag.es

Esteban Fernández-Cobián (Vigo, 1969). Doctor en Arquitectura (2001, Premio CSIC). Profesor Contratado Doctor de la ETSAC, Profesor Invitado de la Universitá di Bologna (2008) y miembro del Comité Científico de la Fondazione Frate Sole (Pavia), es autor de las monografías Arquitecturas de lo sagrado. Memoria y proyecto (2009), El espacio sagrado en la arquitectura española contemporánea (2005), Fray Coello de Portugal, dominico y arquitecto (2001) y A Coruña. Guía de arquitectura (1998), así como de diversos artículos y ponencias en congresos. Ha coordinado las dos ediciones del Congreso Internacional de Arquitectura Religiosa Contemporánea de Ourense (2007 y 2009).

efcobian@udc.es 